\title{
АВТОМАТИЗАЦИЯ ЗАДАЧ БАНКОВСКОГО ОБСЛУЖИВАНИЯ
}

\author{
и.т.н. Бакунова О. М., м.т.н. Бакунов А. М., к.т.н. Образцова О. Н., \\ Носенко А. В., Луцкий В. О., Христофорова А. А., Маркевич В. Ю.
}

Республика Беларусь, г. Минск, Институт информационных технологий Белорусского государственного университета информатики и радиоэлектроники

DOI: https://doi.org/10.31435/rsglobal_wos/31102019/6739

\section{ARTICLE INFO}

Received: 19 August 2019

Accepted: 17 October 2019

Published: 31 October 2019

\section{KEYWORDS}

innovations, developing

technologies, the modern platforms

of programming.

\section{ABSTRACT}

Automated systems used in the banking data accounting process enable the transfer and rapid processing of large amounts of data. However, significant amounts of information are available online for analysis, forecasting, and monitoring. This imposes strict performance requirements on the operating system, database management system, and data transfer facilities.

Citation: Бакунова О. М., Бакунов А. М., Образцова О. Н., Носенко А. В., Луцкий В. О., Христофорова А. А., Маркевич В. Ю. (2019) Avtomatizaciya Zadach Bankovskogo Obsluzhivaniya. International Academy Journal Web of Scholar. 10(40), doi: 10.31435/rsglobal_wos/31102019/6739

Copyright: (C) 2019 Бакунова О. М., Бакунов А. М., Образцова О. Н., Носенко А. В., Луцкий В. О., Христофорова А. А., Маркевич В. Ю. This is an open-access article distributed under the terms of the Creative Commons Attribution License (CC BY). The use, distribution or reproduction in other forums is permitted, provided the original author(s) or licensor are credited and that the original publication in this journal is cited, in accordance with accepted academic practice. No use, distribution or reproduction is permitted which does not comply with these terms.

Введение. Современная жизнь немыслима без использования информационных технологий в самых различных областях жизнедеятельности человека: на производстве, в организациях различного профиля, в научных исследованиях, в процессе обучения. На производственных предприятиях и в других организациях, заинтересованных в увеличении показателя эффективности своей деятельности, программные средства используются для управления и автоматизации различных задач прикладного характера. Среди широкого разнообразия программных средств, используемых организациями для автоматизации решения основных задач их деятельности, можно выделить системы обработки информации, построенные по принципу систем управления базами данных. Системы управления базами данных прошли большой путь развития вместе с вычислительной техникой, и в настоящее время пользуются популярностью. Это связано в первую очередь с их востребованностью в учреждениях и на предприятиях, а также с доступностью персональных ЭВМ для любой организации. Возможности таких систем заключаются в создании на ЭВМ общей базы данных для множества приложений, структурировании этих данных и поддержании их в актуальном состоянии для обеспечения эффективного доступа к ним пользователей в рамках предоставленных полномочий. Потоки информации, которые необходимо обрабатывать таким системам, растут с каждым годом в связи с расширением круга решаемых задач.

Результаты и обсуждение. В настоящее время автоматизированные системы на основе систем управления базами данных широко распространены в банковской сфере. Эти системы позволяют облегчить и улучшить работу сотрудников банка, что является не менее актуальным, чем разработка и использование автоматизированных систем для любой другой сферы деятельности.

В связи со всесторонним развитием информационных технологий в банковской сфере нецелесообразно использовать большие картотеки, рабочую силу и специальные помещения для 
хранения больших объёмов данных. Целесообразнее решить данную проблему с помощью электронно-вычислительных машин; составить программу, предназначенную для упрощения и автоматизации операций, связанных с регистрацией, систематизацией, поиском и обработкой данных банковских операций.

Автоматизированные системы, используемые в процессе учета данных банковских операций, обеспечивают передачу и быструю обработку больших объемов данных. При этом значительные объемы информации доступны в оперативном режиме для анализа, прогнозирования и контроля. Это предъявляет жесткие требования к производительности операционной системы, системы управления базами данных и средств передачи данных. Поэтому средства системы должны быть в состоянии поддерживать доступ к большим (и постоянно возрастающим) объемам данных без потери производительности.

На современном этапе развития автоматизированных систем все большее распространение получает распределенная обработка информации. Этому способствует бурное развитие компьютерной техники, снижение ее стоимости, простота в обслуживании и эксплуатации.

Структурно такие автоматизированные системы реализуются как некоторая сеть (вычислительная система), объединяющая посредством каналов передачи данных персональных электронно-вычислительных машин терминалы, другие периферийные устройства.

Автоматизированные системы, с точки зрения прикладных потребительских свойств, могут обладать достаточной широтой функционального набора. При этом в современных условиях развития банковских систем большое значение имеет соответствие используемых программных средств требованиям интегрированности, конфигурируемости, открытости и настраиваемости.

Конфигурируемость автоматизированных систем означает возможность использования различных конфигураций системы (минимальной с последующим расширением путей введения дополнительных модулей). При этом должны учитываться такие характеристики системы, как набор модулей и реализуемых ими функций, степень автономности модулей, наличие межмодульного взаимодействия и формы его реализации (почта между модулями, пересылка управляющих сообщений и другое), возможные конфигурации системы, ее минимальный состав, независимо функционирующие части, варианты расширения.

Интегрированная автоматизированная система объединяет все банковские процессы, повышая уровень управляемости банком. Такая система адекватно отражает все функциональные и информационные связи, существующие в банке, обеспечивает доступ к данным любого уровня, тем самым предоставляя возможность контролировать работу банка с необходимой степенью детализации.

Часто сотрудники банков прибегают к автоматизации различных потоков документооборота с помощью разных продуктов. Но и в этом случае возникает необходимость выработки единых корпоративных стандартов и требований к различным частям единой системы автоматизации документооборота. Необходимо добиться, чтобы система, состоящая из программного обеспечения разных фирм-разработчиков, имела целостную структуру, поддерживающую единый системный документооборот.

Остановимся на некоторых, свойственных банковской сфере специфических моментах. Банк, являясь финансовым агентом, по сути своей - обслуживающая организация. Исходя из этого, в дальнейшем будем опираться на отношения двух основных субъектов - банка и клиента.

Обработка информации в банке осуществляется в рамках автоматизированной банковской системы обработки информации. Документооборот в банке можно условно разделить на два основных потока: административный и операционный.

Административный документооборот не пересекается с обслуживанием клиентов, а направлен на обслуживание деятельности самого банка, его внутренней отчетности и финансовых операций. Операционный поток направлен на обслуживание клиентов. Здесь обрабатываются финансовые документы клиентов, их заявки, договора и прочее.

Остановимся подробнее на втором потоке документооборота, связанного с основной деятельностью банка. Надо отметить, что многие методы обработки документов приемлемы как для административного, так и для операционного потоков документооборота.

Поскольку банк состоит из множества отделов, занимающихся ведением и учетом различных по сути операций, это накладывает определенные требования и ограничения на автоматизацию документооборота в рамках каждого отдела. Работники кассового узла 
занимаются не только приемом документов от клиентов, но их деятельность также связана с обработкой наличности [16].

Основные функции данной системы предусматривают защиту от несанкционированного входа в систему, работу в сетевом и автономном режимах, получение информации по устройствам в реальном времени, формирование отчетов на основание проведенных платежей, получение логов от устройств. Также требуется наличие специальной поисковой системы для быстрого и эффективного поиска необходимой информации.

Программное средство должно быть разработано для функционирования в среде операционной системы Windows, работать в среде терминальных приложений. Программный продукт необходимо снабдить отказоустойчивой системой, защищенной от несанкционированного доступа, интуитивно-понятным интерфейсом и интерактивным руководством, помогающим пользователю разобраться с особенностями работы с программой.

Выводы. Автоматизированная система внедрена вместе с системой терминальных приложений: пользователь на рабочем месте имеет не полноценный персональный компьютер, а только терминальный клиент (тонкий клиент), который посредством комплекса программноаппаратных средств подключается к терминальному серверу, где и происходит запуск программного продукта. Данный способ позволяет улучшить защиту базы данных и самой программы от несанкционированного доступа, упростить администрирование рабочего процесса, ускорить работу с базой данных, так как локальная сеть (ЛВС) не будет загружена множеством запросов-ответов при работе с базой данных, а только лишь передавать данныепакеты протокола RDP (протокол удаленного рабочего стола). Так же увеличивается отказоустойчивость системы в целом: сведен к минимуму вариант сбоя автоматизированной системы при неисправности рабочей станции или ЛВС, в случае с терминальным приложением, происходит только отсоединение текущего сеанса, без некорректного выхода из приложения. Так же уменьшаются затраты на электроснабжение рабочих станций: тонкие клиенты потребляют значительно меньше электроэнергии, и уменьшаются затраты на формирование новых рабочих мест: стоимость терминального клиента ниже и он не требует установки мощных источников бесперебойного питания.

\section{ЛИТЕРАТУРА}

1. О. М. Бакунова, О. Н. Образцова, Силинский, Р. А. Дистанционные технологии как способ оптимизации трудовых процессов инженеров испытательной лаборатории / // Дистанционное обучение - образовательная среда XXI века : материалы X международной научно-методической конференции (Минск, 7 - 8 декабря 2017 года). - Минск: БГУИР, 2017. - С. 286.

2. Бакунова, О. М., Калитеня, И. Л., Тимофеев, Д. О., Уласович, В. Ю., Ухналев, Р. Ю., Михаленко, В. А. Возможность использования искусственного интеллекта в банковской сфере // Web of Scholar. - 2018. - 4(22), Vol.1. - Pp. 13 - 15.

3. Bakunova, O. M., Lisovskiy, A. A., Mazur, A. D., Tsimafeyeu, D. O., Pratsko, D. E., Kaliaha, U. V., Kryzhanouskaya, Y. A. Software tool "FILING CABINETS" // Proceedings of the Second International Conference of European Academy of Science, Bonn, November 20 - 28 2018. - Bonn, 2018. - С. 21 - 22.

4. Бакунова О.М., Калитеня И.Л., Уласович В.Ю., Тимофеев Д.О., Ухналев Р.Ю., Михаленко В.А. Интеграция информационных систем с использованием Mule ESB. Web of Scholar. - 2018. - 4(22), Vol.1. - Рp. 4 - 7.

5. Закон Республики Беларусь от 28.12.2009 № 113-3 «Об электронном документе и электронной цифровой подписи»

6. Хаф, Л. Проектирование информационных систем / Л. Хаф. - М.: Бином, 2016 - 728 с. 